\title{
The Spatial Structure of Household Income Level in Guangzhou Based on Housing Rent
}

\author{
Yang Wang ${ }^{*}$, Hong'Ou Zhang, Yuyao Ye, Lixia Jin , and Gengzhi Huang \\ Guangdong Open Laboratory of Geospatial Information Technology and Application, \\ Guangzhou Institute of Geography, China \\ *Corresponding author: Yang Wang, Doctor, wyxkwy@163.com
}

\begin{abstract}
Based on demographic data from the newly available 6th census of 2010 in Guangzhou metropolitan areas, China, we established an alternative method of evaluating residential income level by using housing rent in urban statistical areas. Then we analysed the differentiation pattern and spatial structure of household income level. Finally, we explored the differentiation rule of household income level in 4 ring-layers. We found the following results. The spatial pattern of income level of Guangzhou, gradually better form periphery to centre, shows a significant spatial imbalance. The 'ring-layer' spatial differentiation structure and 'fan-shaped' extending structure are coexisting. Furthermore, the historical process of urban development, the evolution of urban function structure, and differentiation of housing prices are the core driving factors for the formation of spatial structure of household income level in Guangzhou.
\end{abstract}

Key words: social space; income level; housing rent; spatial evaluation; Guangzhou

\section{Introduction}

The spatial structure of urban income level is a core content of urban social geography study, it has always been a hotspot of overseas study, ${ }^{1-2}$ and is increasingly emphasized by the urban researchers in China. The western research on urban residents' income hierarchy structure started from the three major classical models of Chicago School. Shevky and Williams first clearly proposed the concept of urban social area, ${ }^{3}$ then studied out the spatial variation of residents' economic status by means of the demographic data and classified social area by that, and started the deductive analyses on urban income hierarchy space zoning. This stage was dominated by the ecological school of human beings, and its research route was analysis on demographic data. After that lots of empirical case studies sprang out, and the behavioral school, structuralism school, humanism school, Neo-Marxism school, Neo-Weberism School, landscape school, social ecology school, location theory school and time-geography school, etc were established in accumulations and summarizations.

The scholars depicted the income level spatial variation pattern of Chinese cities through case studies on China, for example the high income community and low income community in Beijing, ${ }^{4}$ the high social economic status residential community and agricultural population residential community in Shanghai, ${ }^{5}$ and the medium-level income class concentration community, general wage-earning class residential community, intellectual and senior professional concentration community in Guangzhou, ${ }^{6}$ etc. Almost each empirical study has different social zoning methods and results. However, these diversified results have caused difficulty to the comparative study between cities. Because the demographic census data in China still not involve the income information, which has posed difficulty to the urban 
internal income spatial structure study, therefore, strongly operable and scientific qualitative methods need to be sought for analyzing the urban income class spatial structure in China and it has very significant academic significance.

Based on this, an optional spatial evaluation method of urban income level is proposed in this article. We construct the comprehensive evaluation system of household incomes on the basis of the housing rent level, and obtain the income level score for a certain area. We also take subdistrict as the study unit, and evaluate the income level variation pattern in Guangzhou City. This method could provide a strongly operable idea for the study of urban internal space.

\section{Data and methods}

\subsection{Study area and data sources}

The study area of this paper is surrounded by the Guangzhou Ring Expressway, GuangzhouGaoming Expressway, and Guangzhou municipal boundary (Fig.1). The area, including 118 subdistricts or towns (hereinafter referred to subdistricts), is the city function region of Guangzhou. The population size of the study area is 8280 thousand by newly available 6th census of 2010. On the basis of the construction and development of Guangzhou, we divided the study area into old area, core area, urban area, and suburb from center ring-layer to the periphery ring-layer. The population sizes of above mentioned 4 areas are respectively 800 thousand, 1690 thousand, 3470 thousand, and 2320 thousand. The data comes from Guangzhou Bureau of Statistics and "Tabulation on the 2010 Population Census of Guangzhou City”.

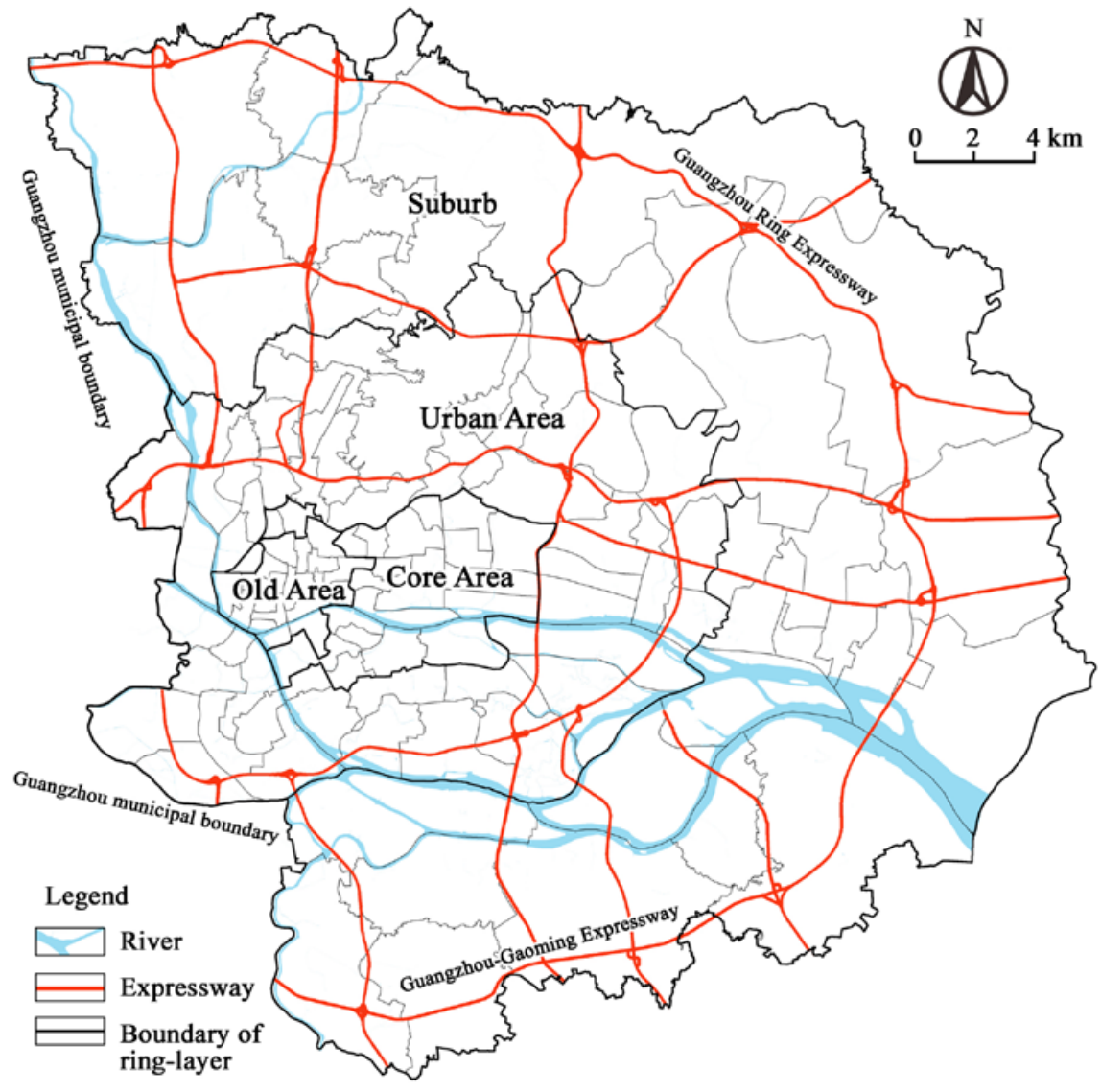

Fig. 1 -The spatial scope and it’s division of territory 


\subsection{Research method}

Due to the lack of indicators of income in 6th census of 2010 in Chinese cities, we used housing monthly rents of household (hereinafter referred to as housing rent) to reflect the household income levels. By the data of household housing rent from 6th census of 2010 in Guangzhou City, we found that the histogram (Fig.2) of housing rent have normal distribution.

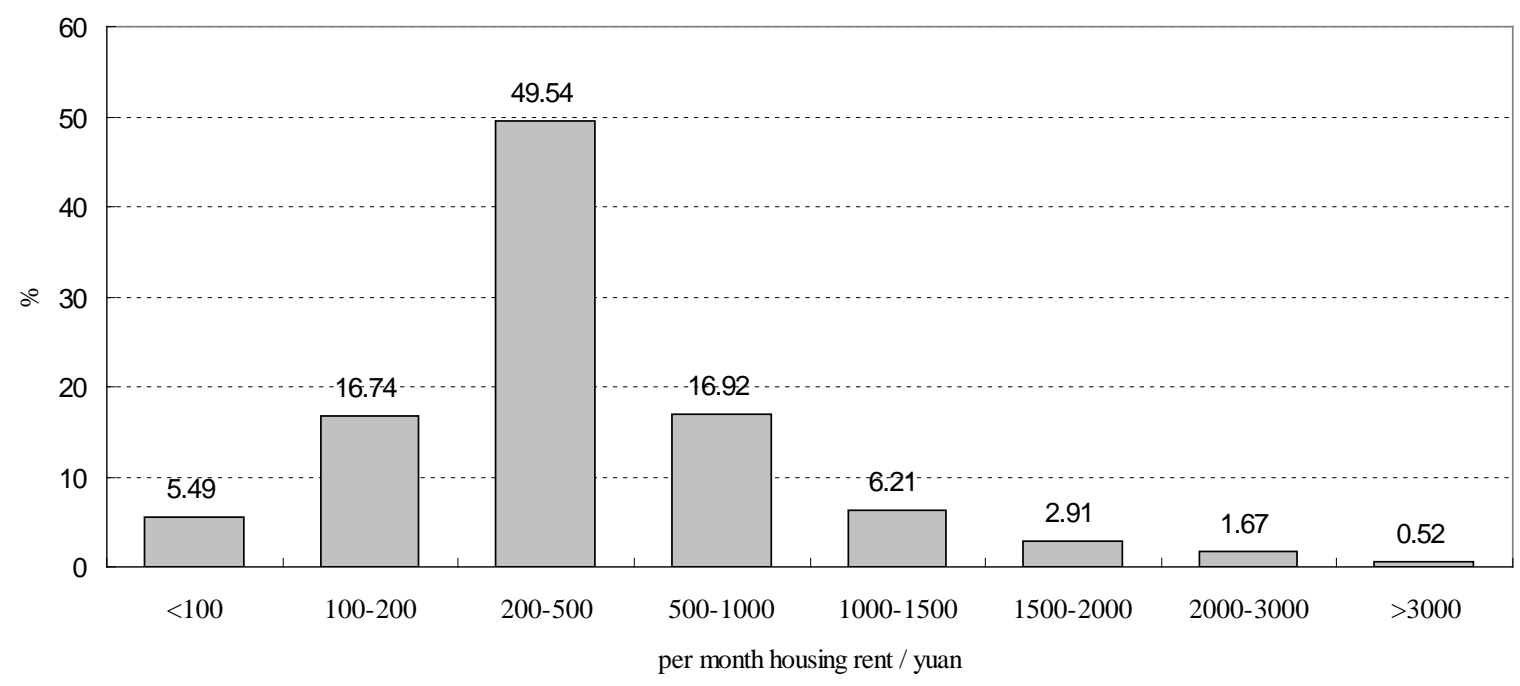

Fig. 2 -The histogram of housing rent in Guangzhou

Based on common sense, we assume that the higher affordability of rent of a given renter, the higher the renter's income. On the basis of the hypothesis, we mapped grade of the housing rent to income score (on a scale of 1 to 9) (Table 1 ).

Table 1 -The corresponding relation between scopes of housing rent and income scores

\begin{tabular}{|l|r|r|r|}
\hline $\begin{array}{l}\text { The scopes of } \\
\text { housing rent (yuan) }\end{array}$ & Income scores & \multicolumn{2}{|l|}{$\begin{array}{l}\text { The number of household } \\
\text { (household) }\end{array}$} \\
\hline$<100$ & 1 & 6363 & \multicolumn{2}{l|}{$\begin{array}{l}\text { The proportion of total } \\
\text { household (\%) }\end{array}$} \\
\hline $100-200$ & 2 & 19395 & 16.74 \\
\hline $200-500$ & 3 & 57393 & 49.54 \\
\hline $500-1000$ & 4 & 19605 & 16.92 \\
\hline $1000-1500$ & 5 & 7194 & 6.21 \\
\hline $1500-2000$ & 6 & 3367 & 2.91 \\
\hline $2000-3000$ & 8 & 1933 & 1.67 \\
\hline$>3000$ & 9 & 597 & 0.52 \\
\hline
\end{tabular}

Hence the score of income level of a given subdistrict can be written as follows:

$$
I L=\sum_{i=1}^{n} x_{i} f\left(x_{i}\right)
$$

where the higher the score of $I L$ (on a scale of 1 to 9) of a given subdistrict, the higher of it's income level. $x_{i}$ stands for the $i$ th score of income level of a given subdistrict; $n$ is the number of subdistricts; and $f\left(x_{i}\right)$ represents the population share of income level $i$ of household. $f\left(x_{i}\right)$ can be written as:

$$
f\left(x_{i}\right)=p_{i} / \sum_{i=1}^{n} p_{i}
$$

where $p_{i}$ is the number of ith income level households. 


\section{Results and discussion}

\subsection{The spatial pattern of household income level in Guangzhou}

Based on the method we proposed, we calculated the income level scores of subdistrict in Guangzhou. Using the technique of GIS, we divide 5 levels into high-income districts, the middle-higher income districts, the middle-income districts, the middle-lower income districts and the low income districts. Then the spatial pattern of household income level in Guangzhou is shown as Fig.3. We found that the income level of the core area and its northern expansion is the highest. The high-income subdistricts are Shahe, Linhe, Tianhenan, Meihuacun, Baiyun, Liede, Xingang, Zhanqian, and Tianyuan. These subdistricts are located in core area except Tianyuan subdistrict. In sum, the 'ring-layer' spatial differentiation structure and 'fan-shaped’ extending structure are coexisting in Guangzhou.

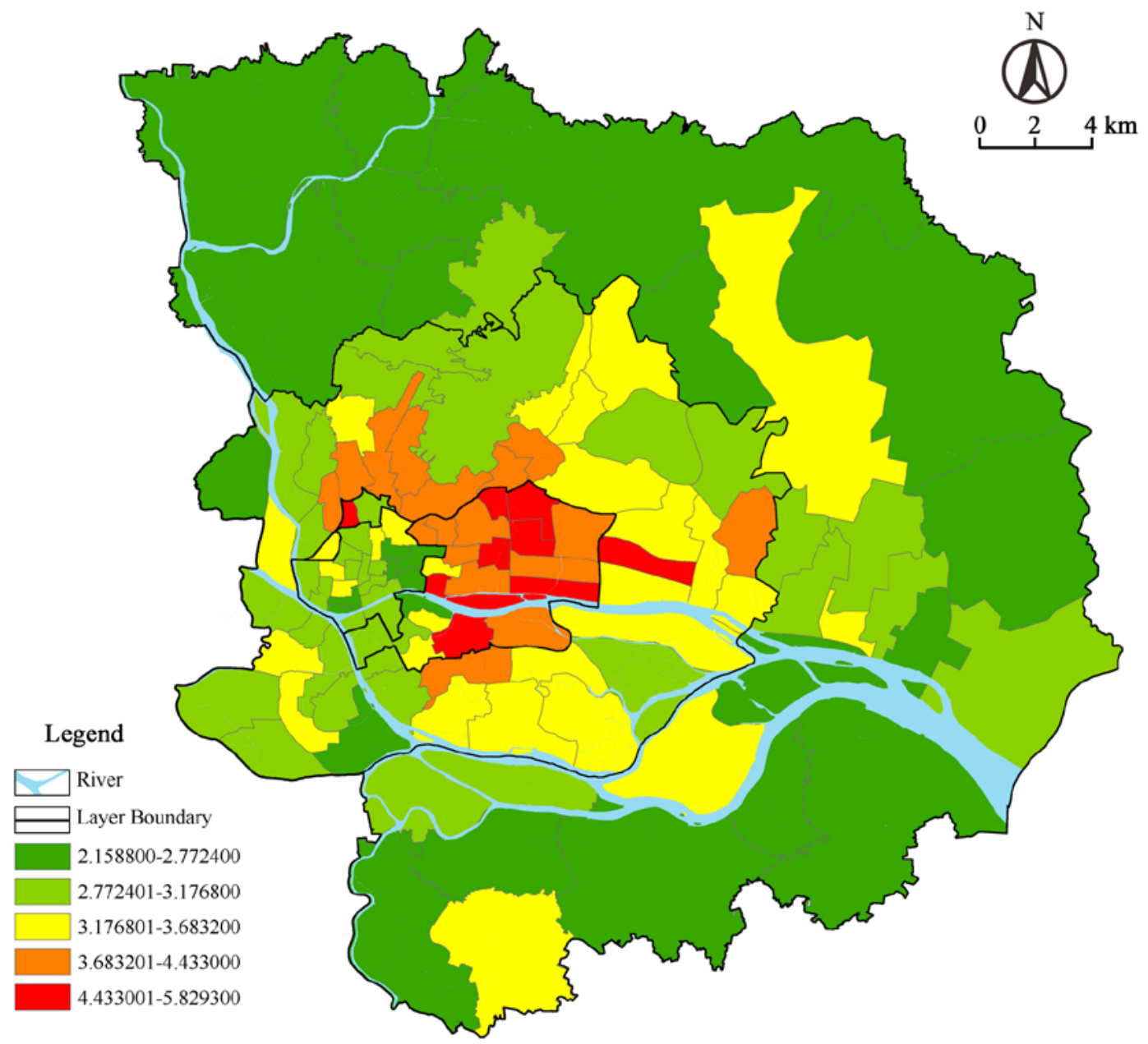

Fig. 3 -The spatial pattern of household income level in Guangzhou

The forming reason of this differentiation pattern is the distinction of leading function in 4 ring-layer. The CBD is located in the core area, and the industry of core area has higher in additional value, so the high-income subdistricts are gathered in the core area.

\subsection{The income feature of each circle layer in Guangzhou}

We calculated the average income scores of old area, core area, urban area, and suburb respectively (Table 2). The results show that the core area is the top-scoring; the urban area is the second-highest score, but has a large gap with the core area; the suburb is the lowest score. 
In addition, we draw the BOX diagram of income scores in the respective circle area (Fig. 4) and found that the income level, gradually better form periphery to centre, shows a significant circle-layer imbalance. The order from high to low of household income level is core area, urban area, old area, and suburb.

Table 2 - Average scores of income level in each circle layer in Guangzhou

\begin{tabular}{|l|r|r|r|r|}
\hline & Old area & Core area & Urban area & Suburb \\
\hline Average income scores & & 2.9437 & & 4.0995 \\
\hline
\end{tabular}

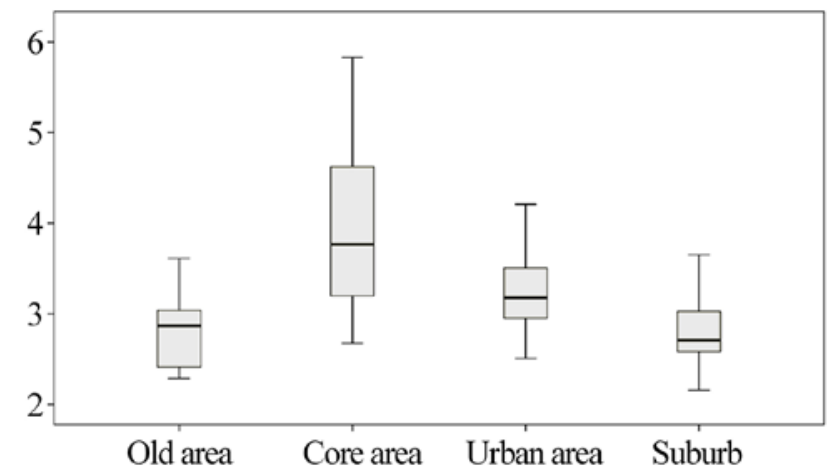

Fig. 4 -The BOX diagram of income scores in respective circle area in Guangzhou

The formation of spatial structure is driven by the historical process of urban development and the evolution of urban functional structure. The old area is the urban built-up area in 1930s. After 1949, urban construction land expanded eastwards, and the population moved eastwards to the core area. Since 2000, the gravity of urban construction land moved eastwards again. The building of Zhujiang New Town (CBD) and its surrounding residential districts attracted a large number of high-income households settled. Meanwhile, the redevelopment of old area has become increasingly difficult. The phenomena make the dwelling quality decrease. In addition, the spatial structure of household impact the spatial structure of the housing price.

\section{Conclusions}

We provided an alternative method of spatial evaluating residential income level. A comprehensive evaluation system is provided by using housing rent in urban statistical areas. Then the income score can be calculated by housing rent score. The method could provide a strongly new idea for the study of urban internal social space.

The spatial pattern of income level of Guangzhou, gradually better form periphery to centre, shows a significant spatial imbalance. The 'ring-layer' spatial differentiation structure and 'fan-shaped' extending structure are coexisting. Furthermore, the historical process of urban development, the evolution of urban function structure, and differentiation of housing prices are the core driving factors for the formation of spatial structure of household income level in Guangzhou.

\section{Acknowledgements}

This research was financially supported by the National Natural Science Foundation of China (41401164; 41571128), the Technology Plan of Guangzhou (201609020002; 201709020007), the Scientific Platform and Innovation Capability Construction Program of GDAS 
(2016GDASPT-0210), and the High-level Leading Talent Introduction Program of GDAS (2016GDASRC-0101).

\section{References}

1. R. Flock, W. Breitung, L. X. Li, Commodity housing and the socio-spatial structure in Guangzhou: A Study Based on Estate-Level Residential Property Prices, China Perspectives. 2(2013): 41-51.

2. P. Doreian, N. Conti, Social context, spatial structure and social network structure, Social Networks. 34(2012): 32-46.

3. E. Shevky, W. Bell, Social Area Analysis. Stanford University Press, Stanford, 1955, str. 27-95.

4. C. L. Gu, F. H. Wang, G. L. Liu, Study on urban social areas in Beijing, Acta Geographica Sinica. 58 (2003):917-926.

5. G. F. Xuan, J. G. Xu, J. Zhao, Social areas of the central urban area in Shanghai. Geographical Research, 25(2006):526-538.

6. C. S. Zhou, Y. Liu, H. Zhu, Analysis on social areas of Guangzhou City during the economic system transformation, Acta Geographica Sinica. 61(2006):1046-1056. 